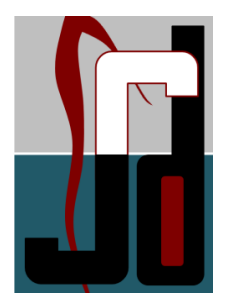

\title{
REVIEW
}

\section{Nanotherapeutics in Oncology: Dendrimers the Nano Wonder}

\author{
Jeelani $\mathrm{S}^{1}$, John Baliah ${ }^{2}$
}

ABSTRACT: Cancer is one of the leading causes of death in the world. The research in the field of Oncology is a never ending journey. Emerging among the existing management modalities in Oncology is an enticing advance Dendrimers as part of Nanotechnology. Simulating the concept of Trojan horse strategy are the nano molecules, Dendrimers which possess a design that provide a tailored sanctuary containing voids that provide a refuge from the outside environment wherein the anti cancer drug molecules can be physically trapped and target the cancerous cells specifically sparing the adjacent normal cells thus serving as an ideal technology in defending the disaster cancer.

Keywords: nanotherapeutics, oncology, dendrimers

\section{A \\ $\mathcal{L}_{\mathrm{s}}$ a reflection of enticing technology}

which has progressed in leaps and bounds are the fascinating wonder molecules of $21^{\text {st }}$ century under the umbrella of Nanotechnology confronting confounding potential real world challenges.

The research in cancer Diagnostics and therapeutics over many decades has evolved multifariously and despite intense scientific efforts in the discovery, development and design of anti cancer therapeutic agents, the disaster cancer poses an extraordinary challenge even to the most intellectual scientific professionals.

Tackling this unique challenge is a dream technology in infancy a nano dream in the form of Nanowonder molecules - Dendrimers.

\section{HISTORY OF DENDRMERS}

It dates back to 1978 when Vogtle and co workers studied about Cascade reactions. Cascade synthesis is defined as reactions " where a functional group such as amine is made to react in such a way as to appear twice in the subsequent molecule or product $[1]$.

Inspired by the Leuwenberg model of arboreal design, Newkome and co workers reported the synthesis of Cascade molecules - synthetic macromolecular tree like molecules "Arborals" (Latin: "Arbor 1/4 tree)

Most interesting was that these molecules were shown to possess cavities for encapsulation of guest molecules such as drugs ${ }^{[2]}$.

Then subsequently in 1986, Tomalia and co workers coined the name "Dendrimers"(Greek: 
Dendron $1 / 4$ branch or tree like) for radially symmetric branched molecules and most significantly portrayed the application of Cascade synthesis for the synthesis of Dendrimers ${ }^{[3]}$.

\section{DENDRIMER CHEMISTRY AND} SYNTHESIS

Dendrimers consists of major regions - an initiator core, a shell with extending arms or branches made of building blocks, exterior or outermost surface groups on the termini of the branches ${ }^{[4-6]}$.

\section{DENDRIMER SYNTHESIS}

Dendrimer can be synthesised by 2 major approaches - the Divergent approach and Convergent approach. In the divergent approach, used in early periods, the synthesis starts from the core of the Dendrimer with a limitation in that only one type of reaction could be performed using dendrimers synthesised by this method. This gave rise to the convergent method of synthesis Pioneered by Frechet and co workers wherein synthesis starts from the exterior ${ }^{[7]}$.

The approach is versatile in that there is possibility of simultaneously conjugating appropriate targeting moieties, drugs and imaging agents thus offering multifunctional nano device to target, deliver and monitor the progression of therapy ${ }^{[8]}$.

Ultimately the convergent method of Dendrimer synthesis enables multifunctional conjugates without marked systemic immunogenicity with the help of Genetic engineering ${ }^{[9,10]}$.

\section{PRINCIPLE OF NANOTHERAPEUTICS}

Nanotechnology is the convergence of multifarious fields including biology, applied physics, optics, computational analysis, modelling and material science.

The fundamental principle regarding the exact size of anti cancer therapeutic molecules that should diffuse through the vascular pores reach the tumour site remain unclear. This has led to the designing of nanotherapeutics - Dendrimers which are well defined structures ranging from 1-10 nm in diameter $^{[11-13]}$.

A hallmark of Cancer aberrant glycosylation is being exploited with Dendrimers scaffolds which provide a uniform to control the multimeric carbohydrate presentation needed to enact the "Cluster Glycoside effect" which is crucial for targeting the diseased tissues found in Cancer ${ }^{[14-21]}$.

\section{Lock and Key mechanism and Molecular recognition}

A fundamental process in the existence of life is the concept of molecular recognition based on the complementarity between receptors and substrates similar to the lock and key function described by Emil Fischer over centuries ago. In biological science Lock is the molecular receptor and key is the substrate - drug.

By virtue of their inherent ability to achieve 
molecular recognition of biological features the dendrimers can be exploited for the recognition of surface biomarkers that distinguish cancer cells from healthy cells ${ }^{[22-24]}$

By virtue of Molecular pumps Cancer - the crab like growth is been stubborn at many occasions to the existing therapeutic modalities. Hence the ultimate objectives of an ideal therapeutic are their ability to target specifically the involved cancerous cells, image the extent of cancer, sense its signatures, deliver the therapeutic and finally monitor cells for their response which is served by the nanotherapeutics and Dendrimers are one such successful evolution fulfilling this concept ${ }^{[25-27]}$.

\section{BIOCOMPATIBILTY OF DENDRIMERS}

Beyond the unique aspects that Dendrimers deserve the most promising aspect of Dendrimers is its Biocompatibility which is reflected by water solubility, lack of immunogenicity and toxicity. By virtue of being highly hydrated macromolecular structural dendrimers tend to be less immunogenic. The solubility can be subsequently adjusted by surface modifications or by the addition of conjugated ligands.

Last and most moral aspect is its least toxicity which dendrimers by virtue of the building blocks themselves and their degradation products upon delivery and release of the drug pay load are considered to be non toxic both non specific and systemic. This has been made possible by using natural biological molecules such as carbohydrates, amino acids and peptides, nucleic acids and lipids as the building blocks.

By virtue of molecular pumps Cancer - the crab like growth is been stubborn at many occasions to the existing therapeutic modalities.

Hence the ultimate objectives of an ideal therapeutic are their ability to target specifically the involved cancerous cells, image the extent of Cancer, sense its signatures, deliver the therapeutics and finally monitor cells for their response which is served by the nanotherapeutics. And Dendrimers are one such successful evolution fulfilling this concept ${ }^{[28-38]}$.

THE DUAL FACE OF THE NANOWONDER

\section{DENDRIMERS}

Encapsulation and Conjugation are the treasured dual face of the dendrimers. A spherical branching structure built from a starting atom - nitrogen to which carbon and other elements are added by repeated series of chemical reactions are the Dendrimers ${ }^{[39-41]}$ wherein hyper branching going from the centre towards the periphery results in a design that can provide a tailored sanctuary containing voids that provide a refuge from the outside environment wherein drug molecules can be physically trapped which reflects the cunning face of dendrimers ie, the concept of 
encapsulation $^{42}$. Studies reveal that drugs such as 5 fluorouracil, 5 amino salicylic acid, pyridine, mefanamic acid and diclofenac, paclitaxel, docetaxel and the anti cancer agent 10 hydroxycamptothecin have been encapsulated successfully ${ }^{[43-46]}$.

The release of the encapsulated guest molecules ie, the drugs occurs once they reach the intended site by hydrolytic degradation of the dendrimer in aqueous conditions and the guest molecules can be liberated at different states thus rendering slow and rapid release drug delivery ${ }^{[47]}$.

Apart from encapsulation, to reflect the dual face of the dendrimers is the concept of conjugation. This has been made possible by the inclusion of ligands which are intended to bind specifically to cancer cells. Folate is appropriately considered as a Tumor targeting ligand, because the membrane bound folate receptor is over expressed on a wide range of human cancer. Also notably they have good solubility binding to its receptor with high affinity when conjugated with diverse conjugates including radioactive imaging agents, MRI contrast agents and gene transfer vectors ${ }^{[48-52]}$.

Supporting and reinforcing the dual face of the dendrimers is the EPR effect - the enhanced permeability and retention effect. It is based upon pathological features of cancer such as extensive angiogenesis resulting in hypervascularization, limited lymphatic drainage and increased permeability to lipids and macromolecules. The advances in Nanotechnology with the ability to construct monodisperse particles of dendrimers in the appropriate size range required to exploit the EPR effect wherein the ability to tune surface properties provide a gateway to dendrimers with favourable properties for targeting the cancer specifically $^{[53-56]}$.

\section{BORON NEUTRON CAPTURE THERAPY (BNCT)}

It is a binary radiation therapy where the beam of low energy neutrons is given to a stable isotope of Boron (Boron 10) after they have accumulated in the tumour cells. Boron present in or adjacent to the tumour cells disintegrates after capturing a neutron thereby producing high energy heavy charge alpha particles and recoiling lithium 7 nuclei that destroy only cells in proximity to it primarily cancer cells leaving adjacent normal cells largely unaffected. In contrast conventional techniques where 1700 born derivatives deposition was possible, when dendrimers were used a 3 fold increase in boron deposition proved advantageous. Thus a demanding situation where thousands of ligands are required per targeting antibody is provided by BNCT wherein dendrimers serves as an innovative backbone in anti cancer strategy ${ }^{[58-60]}$ 


\section{GENE DELIVERY}

Also interestingly in infancy are an effort to exploit dendrimers for gene delivery wherein the fractured form of PAMAM known as Superfect is one such design. ${ }^{[61-63]}$

\section{CONCLUSION:}

An integrated look at the multiple considerations required for successful application of any technology for cancer therapy is sometimes frustrating as the anti cancer agent must first be able to seek out subtle changes that distinguish a transformed cell from the other innumerable types of healthy cells found in close proximity.

Thus an ideal therapeutic agent should be able to target only the involved cancerous cells sparing the adjacent normal cells and serving this ideal concept are the nanoparticles dendrimers employing the Trojan horse strategy which dates back to the ancient Greek history when Odysseus of Greece captured Troy by constructing a large wooden horse with a hollow interior housing his Greek warriors. Simulating the same concept but smallest in size are the Nano wonder molecules Dendrimers with a design that can provide a tailored sanctuary containing voids that provide a refuge from the outside environment wherein drug molecules can be physically trapped and target the cancerous cells perse specifically thus serving as a cunning trick that has been employed by scientist in deceiving and defending the disaster cancer. ${ }^{[64]}$

\section{REFERENCES}

1. BuhleierE, Wehner W, Vo"gtleF."Cascade"and"nonskid-chain-like"synthesis of molecular cavity topologies.Synthesis.1978;155-158.

2. Newkome G.R , Z.Yao,Baker G.R,Gupta V. K,Micelles.Part1.Cascade molecules:A new approach to micelles.A[27]arborol.J.Org.Chem.1985;50:2003-2004.

3. Tomalia D. A, Baker H, Dewald J, Hall M, KallosG, Martin S, Roeck J, Ryder J, Smith P, Dendritic macromolecules:Synthesis of starburst dendrimers. Macromolecules.1986;19: 2466-2468.

4. Tomalia D. A, Durst H. D. Genealogically directed synthesis - Starburst cascade dendrimers and hyperbranched structures. Top.Curr.Chem.1993;165:193313.

5. Miller T. M, Neenan T. X. Convergent synthesis of monodispersedendrimers based upon 1,3,5- trisubstituted benzenes.Chem.Mater.1990;2:346-349.

6. Haag R, Stumbe J.F, Sunder A, Frey H, Hebel A.An approach to core-shell-type architectures in hyperbranchedpolyglycerols by selective chemical differentiation.Macromolecules 2000;33:8158-8166.

7. Hawker C. J, J. M. J. Fre'chet, Preparation of polymers with controlled molecular architecture. A new convergent approach to dendritic macromolecules. J. Am.Chem.Soc.

1990;112:7638-7647.

8. Morgan J. R, Cloninger M. J.Heterogeneously func- 
tionalized dendrimers. Curr.Opin.Drug Discov.Devel. 2002;5:966-973

9. Gonzales N. R, De Pascalis R, Schlom J, KashmiriS. V. S. Minimizing the immunogenicity of antibodies for clinical application. Tumour Biol. 2005;26:3143.

10. Matthey B, Engert A, Barth S. Recombinant immunotoxins for the treatment of Hodgkin's disease (Review). Int. J. Mol. Med. 2000; 6:509-514.

11. Kong G, Braun RD, Dewhirst MW. Characterization of the effect of hyperthermia on nanoparticle extravasation from tumorvasculature.Cancer Res. 2001;61:3027-3032.

12. Kong G, Braun RD, Dewhirst MW. Hyperthermia enables tumor-specific nanoparticle delivery: effect of particle size. Hyperthermia enables tumor-specific nanoparticle delivery: effect of particle size. Cancer Res.2000;60:4440-4445.

13. Bilbao R, Bustos M, Alzuguren P, et al. A bloodtumor barrier limits gene transfer to experimental liver cancer: the effect of vasoactive compounds.Gene Therapy. 2000;7:1824

14. Yarema K. J, Bertozzi C. R. Chemical approaches to glycobiology and emerging carbohydrate-based therapeutic agents. Curr.Opin.Chem.Biol.1998;2:49_ 61.

15.Lundquist J. J, Toone E. J.The cluster glycoside effect. Chem. Rev. 2002;102:555-578.

16.Kiessling L. L, Pohl S. Strength in numbers: Nonnatural polyvalent carbohydrate derivatives. Chem. Biol.1996;3:71-77.
17. DennisJ. W, Laferte S, Waghorne C,Breitman M. L, Kerbel R. S. ß1-6 branching of Asn-linked oligosaccharides is directly associated with metastasis. Science 1987;236-239.

18. Sell S. Cancer-associated carbohydrates identified by monoclonal antibodies. Hum. Pathol. 1990;21:10031019.

19.Kobata A, Amano J. Altered glycosylation of proteins produced by malignant cells, and application for the diagnosis and immunotherapy of tumours. Immunol. Cell Biol. 2005;83:

$429-439$.

20. Dennis J. W, Granovsky M, Warren C. E. Protein glycosylation in development and disease. BioEssays 1999;21:412-421.

21.Tong L, Baskaran G, Jones M. B, Rhee J. K, Yarema K. J. Glycosylation changes as markers for the diagnosis and treatment of human disease, in Biochemical and Genetic Engineering Reviews, S. Harding (Ed.).Intercept Limited, Andover, Hampshire, UK 2003; pp. 199-244.

22.Chen B, Piletsky S, Turner A. P. High molecular recognition: Design of “'Keys'.Comb. Chem. High Throughput Screen. 2002;5:409-427.

23.Mecke A, Lee I, Baker Jr J. R, HollM. M. Deformability of poly(amidoamine) dendrimers. Eur. Phy. J. E Soft Matter 2004;14:7-16.

24.Farin D, Avnir D. Surface fractality of dendrimers. Angew. Chem. Int. Ed.

Engl. 1991;30:1377-1379

25.Culver KW. Clinical applications of gene therapy for 
cancer. Clin Chem.1994;40:510.

26. Rosenberg SA. The immunotherapy and gene therapy of cancer. J ClinOncol. 1992;10:180.

27.Kukowska-Latallo J, Candido K, Cao ZY, et al. Nanoparticle targeting of anticancer drug improves therapeutic response in animal model of human epithelial cancer. Cancer Res. 2005;65:5317.

28.Palcic M. M, Li H, Zanini D, Bhella R. S, Roy R.Chemoenzymatic synthesis of dendritic sialyl Lewis(x). Carbohydr. Res. 1997;305:433-442.

29.Roberts J. C, Bhalgat M. K, ZeraR. T. Preliminary biological evaluation of polyamidoamine (PAMAM) Starburst TM dendrimers.J. Biomed.Mater. Res. $1996 ; 30: 53-65$

30.Rockendorf N, Lindhorst T. K. Glycodendrimers. Top.Curr. Chem.2001;217:201-238.

31.Crespo L, Sanclimens G, Pons M,Giralt E, Roho M, Albericio F. Peptide and amide bond-containing dendrimers. Chem. Rev. 2005;105:1663-1681.

32.Shchepinov M. S, Udalova I. A, BrigmanA. J, Southern E. M. Oligonucleotide dendrimers: Synthesis and use as polylabelled DNA probes. Nucleic Acids Res. 1997;25: 4447-4454.

33.Nilsen T. W, Grayzel J, Prensky W. Dendritic nucleic acid structures. J. Theoret. Biol. 1997;187:273-284.

34.Hudson R. H. E, Damha M. J. Nucleic acid dendrimers: Novel biopolymer structures. J. Am. Chem. Soc.1998;115:2119-2124.

35.Suzuki Y, Otomo T, OkaziH, Sawai H. Synthesis and properties of a new type DNA dendrimer. Nucleic Acids Symp. Ser.2000;44:125-126.
36.Li Y, Tseng Y. D, Kwon S. Y, EspauxL. D, Bunch J. S, McEuen P. L, Luo D. Controlled assembly of dendrimer-like DNA. Nat. Mater.2004;3:38-42.

37. Al-JamalK. T, Sakthivel T, Florence A. T.Dendrisomes: Vesicular structures derived from a cationic lipidicdendron. J. Pharm.Sci.2005;94:102113.

38.Takeoka S, Mori K, Ohkawa H, Sou K, Tsuchida E. Synthesis and assembly of poly(ethylene glycol)lipids with mono-, di-, and tetraacyl chains and a poly(ethylene glycol)chain of various molecular weights. J.Am.Chem.Soc.2000;122:7927-7935.

39.Pushkar S, Philip A, Pathak K and Pathak D. “DEndrimers : Nanotechnology Derived Novel Polymers in Drug Delivery". Indian J. Pharm. Educ. Res.2006;40(3):153-158.

40.Sakthivel T and Florence A.T. "Adsorption of amphipathic dendrond on polystyrene nanoparticles". Indian J. Pharm.2003;254:23-26.

41. Yiyun C, Zhenhua X, Minglu M and Tonguen X. "Dendrimers as Drug Carriers: applications in different routes of drug”. J. Pharma. Sci.2008;97(1):123143

42. NamaziH, Adeli M.Dendrimers of citric acid and poly (ethylene glycol) as the new drug-delivery agents.Biomaterials.2005;26:1175-1183

43.Tripathi P. K, Khopade A. J, Nagaich S, Shrivastava S, Jain S, Jain N. K.Dendrimer grafts for delivery of 5-fluorouracil. Pharmazie.2002;57:261-264.

44.Ooya T,Lee J, Park K. Effects of ethylene glycolbased graft, starshaped, and dendritic polymers on 
solubilization and controlled release of paclitaxel. J.

Controlled Release.2003;

93:121-127.

45. Ooya T, Lee J, Park K. Hydrotropic dendrimers of generations 4 and 5: Synthesis, characterization, and hydrotropic solubilization of paclitaxel. Bioconjugate Chem.2004;15:

$1221-1229$.

46.Benito J. M, Gomez-GarciaOrtiz Mellet M, C, Baussanne I, Defaye J, Garcia Fernandez J. M. Optimizing saccharide-directed molecular delivery to biological receptors: Design, synthesis, and biological evaluationof glycodendrimer-cyclodextrin. J Am Chem Soc. 2004;126(33):10355-63.

47.Jansen J. F. G. A, Meijer E. W, de Brabander-van den Berg E. M. M. The dendritic box: Shapeselective liberation of encapsulated guests. J. Am. Chem. Soc. 1995;117:4417-4418.

48. ZalipskyS, Mullah N, HardingJ. A, Gittelman J, Guo L, DeFrees S. A. Poly(ethylene glycol)-grafted liposomes with oligopeptide or oligosaccharide ligands appended to the termini of the polymer chains. Bioconjugate Chem.1997;8:111-118.

49.Reddy J. A,Allagadda V. M, LeamonC. P. Targeting therapeutic and imaging agents to folate receptor positive tumors. Curr. Pharm. Biotechnol.2005;6:131 $-150$.

50.Leamon C. P, Reddy J. A.Folatetargeted chemotherapy. Adv. Drug Delivery Rev. 2004;56:1127-1141.

51.Roy E. J, Gawlick U, Orr B. A, Kranz D. M.Folatemediated targeting of $\mathrm{T}$ cells to tumors. Adv. Drug Delivery Rev.2004;56:1219-1231.
52.Choi Y, Thomas T, Kotlyar A, Islam M. T, Baker J. R. Synthesis and functional evaluation of DNAassembledpolyamidoamine (PAMAM) dendrimer clusters with cancer cellspecific targeting. Chem. Biol.2005; 2:35-43.

53.Heuser L. S, Miller F. N. Differential macromolecular leakage from the vasculature of tumors. Cancer.1986;57:461-464.

54.Maeda H, Wu J, Sawa T, Matsumura Y, Hori K.Tumor vascular permeability and the EPR effect in References 39macromolecular therapeutics: A review. J. Controlled Release. 2000;65:271-284

55.Nagayasu A, Shimooka T, Kinouchi Y, Uchiyama K, Takeichi Y, Kiwada H. Effects of fluidity and vesicle size on antitumor activity and myelosuppressive activity of liposomes loaded with daunorubicin. Biol. Pharm. Bull.1994;17:935-939.

56.Tabata Y, Murakami Y, Ikada Y. Tumor accumulation of poly(vinyl alcohol) of different sizes after intravenous injection. J. Controlled Release.1998;50:123-133

57.Barth R. F, Adams D. M, Soloway A. H, Alam F, Darby M. V.Boronated starburst dendrimermonoclonal antibody immunoconjugates: Evaluation as a potential delivery system for neutron capture therapy. Bioconjugate Chem.1994;5:58-66

58.Barth R. F, SolowayA. H. Boron neutron capture therapy of primary and metastatic brain tumors. Mol. Chem. Neuropathol.1994;21:139-154.

59.Liu L, Barth R. F, Adams D. M, SolowayA. H, Reisfeld R. A.Bispecific antibodies as targeting agents for 
Hematother.1995;4: 477-483.

60.Alam F, Soloway A. H, Barth R. F, Mafune N, Adams D. M, Knoth W. H. Boron neutron capture therapy: Linkage of a boronated macromolecule to monoclonal antibodies directed against tumorassociated antigens. J. Med. Chem.1989;32:2326-2330.

61.Hudde T, RaynerS. A, Comer R. M, Weber M, Isaacs J. D, Waldmann H, Larkin D. F, George A. J. Activated polyamidoaminedendrimers, a non-viral vector for gene transfer to the corneal endothelium. Gene Ther.1999;6:939-943.
62.Haensler J, SzokaJr F. C. Polyamidoamine cascade polymers mediate efficient transfection of cells in culture. Bioconjugate Chem. 1993;4:372-379.

63.Kim T, Seo H. J, Choi J. S, Jang H.S,BaekJ.U, Kim K, Park J.S. PAMAM-PEG-PAMAM: Novel triblock copolymer as a biocompatible and efficient gene delivery carrier. Biomacromolecules.2004;5:2487-249 64.DonatoSpedalierem, Sarah S.In Troy C. 1700-1250 BC, Nic Fields.Spedalier, Osprey Publishing. $2004 ; 51-52$
Address for correspondence:

Jeelani S

Reader,

Department of Oral Medicine and Radiology IndraGandhi Institute of Dental Sciences,

Sri Bajai Vidapeeth University

Puducherry

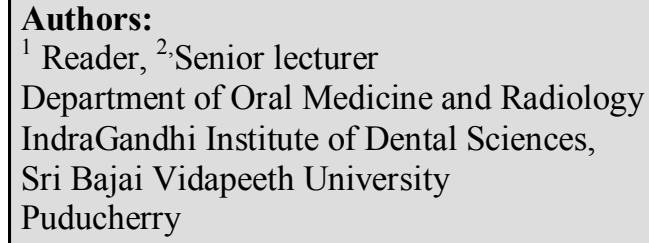

How to cite this article:

Jeelani S, John Baliah. Nanotherapeutics in Oncology: Dendrimers the Nano Wonder. Journal of Scientific Dentistry $2013 ; 3(1): 45-53$

Source of Support: Nil, Conflict of Interest: None declared 